\title{
Purine Antagonist
}

National Cancer Institute

\section{Source}

National Cancer Institute. Purine Antagonist. NCI Thesaurus. Code C1556.

An antimetabolite that affects the metabolism and utilization of purines. 